\title{
Universal Health Coverage and Healthy Living in South-East Nigeria: How Far with Mental Health?
}

\author{
N. Okwudili K. Obayi ${ }^{1}$, Festus Asogwa², Nwachukwu Ugwunna ${ }^{3}$ \\ ${ }^{1}$ Dept of Psychological Medicine, Ebonyi State University, Abakaliki, Nigeria \\ ${ }^{2}$ Dept of Psychology, Federal University Ndufu-Alike Ikwo, Abakaliki, Nigeria \\ ${ }^{3}$ Dept of Community Medicine, University of Nigeria Teaching Hospital, Ituku-Ozalla, Enugu, Nigeria \\ Email: *nokobayi@gmail.com
}

How to cite this paper: Obayi, N.O.K., Asogwa, F. and Ugwunna, N. (2017) Universal Health Coverage and Healthy Living in South-East Nigeria: How Far with Mental Health? Open Journal of Psychiatry, 7, 199-212.

https://doi.org/10.4236/ojpsych.2017.73018

Received: June 29, 2017

Accepted: July 24, 2017

Published: July 27, 2017

Copyright $\odot 2017$ by authors and Scientific Research Publishing Inc. This work is licensed under the Creative Commons Attribution International License (CC BY 4.0). http://creativecommons.org/licenses/by/4.0/

\section{Open Access}

\begin{abstract}
Background: Universal health coverage implies access to key promoting, preventive, curative, and rehabilitative health interventions for all at an affordable cost, thereby achieving equity in access and service. The mentally-ill belongs to a vulnerable group that has not been given adequate attention especially in the south-eastern part of Nigeria. In September 2015, a health summit was organized in Enugu, South-East Nigeria with the sole aim of strategizing towards achieving universal health coverage in the zone. From all indications, much of the efforts being made towards achieving universal health coverage in the zone are geared towards physical conditions with mental disorders being grossly neglected. Purpose: This position paper briefly highlights the burden of mental disorders in South-East Nigeria; brings to fore the numerous challenges/barriers to effective mental health service delivery in the area; and calls for a positive change before a meaningful health coverage can be achieved in the zone (and by extension in the country). Findings: The burden of mental disorders in south-east Nigeria is heavy. Enormous barriers to mental health services in the area range from ignorance and stigmatization to self-marginalization by the unwillingness of many concerned leaders or hospital chief executives in the area to appreciate mental health and employ or increase the number of mental health professionals. Recommendations: All the stakeholders, from policy makers to consumers should wake up, recognize mental health as an indispensable part of health and take urgent and necessary measures that would ensure the promotion of mental health, prevention and treatment of mental disorders, and appropriate rehabilitation of those with mental illnesses in the zone.
\end{abstract}

\section{Keywords}

Universal Health Coverage, Healthy Living, South-East Nigeria, Mental Health 


\section{Introduction}

Mental health is fundamental to health; paramount to personal well-being, family relationships, and successful contributions to society [1]. Hence, its reflection in the definition of health in the constitution of the World Health Organization (WHO): a state of complete physical, mental, and social well-being and not merely the absence of disease or infirmity. The 2005 World Health Assembly defined universal health coverage (UHC) as "access to key promotive, preventive, curative and rehabilitative health interventions for all at an affordable cost, thereby achieving equity in access" [2].

Equity should be implicit within universal health coverage (UHC). However, emerging evidence is showing that without adequate focus on measurement of equity, vulnerable populations may continue to receive inadequate or inferior health care [3]. The mentally-ill is vulnerable and should be recognized as such and strongly considered whenever we are talking of universal health coverage. After all, the slogan that "there is no health without mental health" is a true one.

On $3^{\text {rd }}$ September 2015, a south-east health summit was organized in Enugu, South-East Nigeria. The one day event, organized by the Health Systems Forum (HSF) Nigeria coordinating team and the Health Policy Research Group of the University of Nigeria, Enugu Campus, supported by the Nigeria Federal Ministry of Health and other agencies brought together health workers, policy makers, consumers, and other stakeholders in the health sector within the region. The programme comprised poster presentations, exhibitions, thematic sessions, and a special session. The emphasis was on efforts towards the achievement of universal health coverage in the zone.

\section{Burden of Mental Disorders}

The WHO has reported that one in four people in the world will be affected by mental or neurological disorders at some point in their lives [4]. This is a very significant number for anybody or government to neglect.

Mental, neurological, and substance use (MNS) disorders are prevalent in all regions of the world (including South-East Nigeria) and are major contributors to morbidity and premature mortality. Worldwide, community-based epidemiological studies have estimated that lifetime prevalence rates of mental disorders in adults are $12.2 \%-48.6 \%$, and 12 -month prevalence rates are $8.4 \%-29.1 \%$ [5]. Fourteen per cent $(14 \%)$ of the global burden of disease, measured in disability -adjusted life years (DALYs), can be attributed to MNS disorders. About 30\% of the total burden of non-communicable diseases is due to these disorders [5]. Major contributors are depression, bipolar disorders, schizophrenia, substance use disorders, and dementia and each usually runs a chronic course.

Studies of psychiatric morbidity in Primary Health Care settings in Nigeria gave values ranging from $10.4 \%-40.0 \%$. Persons with serious mental illnesses die on average between 13.5 and 32.2 years earlier than the general population [6]. Unipolar depression-a mental disorder-is one of the three conditions the WHO has projected to be the leading causes of burden of disease by the year 
2030, HIV/AIDS and ischaemic heart disease being the other two. Factors that currently increase mental disorders in South-East Nigeria include, among others, gradual loss of our core values with associated lifestyle changes, increasing unemployment, kidnapping, economic recession, impact of the insurgency in other parts of the nation, and indeed direct attack on the residents by unknown persons. There is also significant burden due to human and economic loss, stigma and its consequences, as well as burden of care for the mentally-ill. Most physical conditions have psychological components. Unfortunately, there is a wide gap between the burden of neuropsychiatric disorders and available resources to address this burden in Nigeria [7] and the gap is much in the southeastern part of the country.

Nigeria went into economic recession that became very obvious by mid-2016 and as at the time of this documentation, the country was yet to come out of the recession. The economic recession, poverty, terrorism, unprecedented killings by unknown persons including increasing community conflicts with herdsmen, and other vices, all pose mental health challenges to Nigerians including those residing in the south-eastern region.

\section{Barriers to Mental Health Services in South-East Nigeria}

There are various factors that pose challenges to the delivery and utilization of mental health services in south-east Nigeria. These include, but are not limited to the following:

Cultural belief: Many communities within the area give different (often false) cultural attributions to the nature, cause, consequences, and management of mental disorders. For instance, in some communities in Igbo land (the tribe that makes up the south-east Nigeria), it is believed that when the mental illness of an individual is such that it takes the individual to the market place, the illness can never be cured. The market is an open place and whatever is brought to the market is no more a secret. The implication of this adage is that the people believe that mental illness (psychotic disorders) should be hidden by the bearer (sick person) and there is no need bothering to treat that mentally-ill that has gone to the open (chronic psychotic conditions). This cultural view, as known and believed by mental health professionals, is erroneous.

Ignorance on the part of the populace, co-medical personnel, and the government: Many (including the well-educated as well as some health workers) are ignorant and/or do not believe that psychiatric conditions are treatable by orthodox means. Notwithstanding the educational status of many people in the area, many believe that the cause of mental illness is not ordinary, that it is either of spiritual origin or due to the handiwork of evil people. With this notion in mind, orthodox treatment is not seen to have any place. Hence, they go ahead to patronize churches/prayer houses and native practitioners and pastors and other clergy men and women (who often cause more harm than good with their false prophesies). Surprisingly, some medical personnel also do not believe that medical science has satisfactory explanation to the aetiology and treatment of mental 
disorders.

Quackery in the area: Many untrained quacks in the area claim to have one form of treatment for mental illness or the other. These range from some pastors or managers of some prayer houses to unqualified 'health workers' to the traditional practitioners. These people attribute one false reason or the other to the aetiology of mental illnesses, often to the handiwork of enemies, making the sufferer believe that his/her illness is of spiritual or man-made origin whose treatment must be far from orthodox. Some prayer houses often tell patients to abandon their drugs, an action that often leads to a relapse.

Government and policy makers often neglect or pay lip service to mental health services: Most hospital chief executives or administrators in the zone prefer to employ non-health professionals to healthcare professionals and many are repugnant to 'mental health' matters. There are public health institutions in the zone (and we believe it is so in many other parts of the country, anyway) with excess numbers of non-clinical staff that have no (or do not know their) job descriptions, often employed for political reasons. Such persons only occupy spaces that would have been provided to skilled health professionals that would add meaningfully to the growth of the institutions by contributing reasonably to the treatment of sick persons. Majority of the primary care centres in the zone do not have any trained mental health personnel.

Inadequate manpower and well equipped facilities [8]: The few professionals engaged in the health sector are all concentrated in the few tertiary institutions, often for remuneration purposes. These tertiary hospitals are mostly located in state capitals, leaving the rural areas as well as a greater part of each state with no mental health facility or personnel.

Stigmatization: The mentally-ill, their families, and the trained professionals who treat them are all being stigmatized against. This stigmatization is mainly due to the unfortunate impression or belief at times that the mentally-ill is responsible for his or her ailment, probably as a result of his or evil acts or that the mental illness was inflicted on the person by an evil one. Either way, many believe that they should distance themselves from the mentally-ill. The mentally-ill could also stigmatize against himself or herself, all leading to barrier to healthcare utilization or service.

Lack of political will on the part of psychiatrists and other mental health experts within the zone: Mental health professionals in the area are also not doing enough to gain recognition by the government and other relevant policy makers. Even in some hospital settings where there are few mental health professionals, some of such professionals do not have enough political muscles to get the attention of the hospital managements to see the need to develop or expand the mental health units or departments.

Inability to actualize the millennium development goals (MDGs): Each of the eight millennium development goals directly or indirectly had a link to good mental health or disorders. Like many other countries, Nigeria was yet to actualize the goals and their targets before the 2015 deadline reached. This non-actu- 
alization of these goals undoubtedly affected the promotion of mental wellbeing of the people. Let us hope that the sustainable development goals (SDGs) which have replaced the MDGs [9] will be maximally achieved in the zone within the time frame.

Poor financing: Only about less than $4 \%$ of the health budget of the Federal Government of Nigeria goes to mental health, with over $90 \%$ of this going to mental hospitals, [10], leaving a large majority of people with mental disorders to no care at all.

Nil to underdeveloped Community Mental Health services: There is a lack of effective functional community mental health services in each of the local government areas or states in the entire zone. Some efforts which seem to have been made in some quarters in the past appear not to have been sustained. The growth in this vital and currently world-accepted mental health care approach has been stunted in the area impairing availability of (and access to) care to one with mental disorder.

Yet to arrive: The few service centres are yet to arrive. Available services are not yet up to the required optimal standard. No centre in the zone has a full functional drug (addiction), geriatric, or child/adolescent unit, for instance. We mean that there is no fully functional centre with all the required personnel plus diagnostic and treatment equipment/tools as obtainable in ideal centres in developed countries. None has adequate facilities for biological psychiatry. Neuroimaging investigations, for instance, are done mainly in private facilities and at prices that majority of the patients can hardly afford. Some of the states do not even have a single centre for such investigations even if the patient or the family can afford to pay.

Lapses or inadequacies in the National Health Insurance Scheme (further explained below) and many other barriers too many to mention or discuss here.

\section{The National Health Insurance Scheme and Mental Health}

The National Health Insurance Scheme (NHIS) in Nigeria was established by a federal government law in 1999 (with implementation commencing in 2005) as a programme to help achieve universal coverage using financial risk protection mechanisms [11] [12]. The NHIS lists among its objectives: to ensure that every Nigerian has access to good health care services, to protect families from the financial hardship of huge medical bills, to limit the rise in the cost of health care services, to ensure equitable distribution of health care costs among different income groups, to ensure equitable distribution of health facilities within the Federation and, to ensure the availability of funds to the health sector for improved services [13]. The NHIS is currently running fairly better in federal hospitals with many state and private organizations yet to be meaningfully involved. But most importantly, only very few patients within the region have access to psychiatric care under the scheme. The scheme is not yet being operated in some centres that attend to a significant number of persons with mental illnesses within the zone. Another reason is that, unlike patients with physical illnesses, 
majority of the people with chronic mental disorders are not gainfully employed and may not easily access the scheme. Nevertheless, there are few key areas in the scheme where people with mental disorders (compared to those with physical illnesses but without mental disorders) are unfortunately disadvantaged.

\section{NHIS and psychiatric drugs}

NHIS recommends that centres can provide only the drugs in the Nigerian essential drug list (EDL). But how far does the EDL accommodate commonly used psychiatric medications? For instance, some atypical (new generation) antipsychotics, which are currently more commonly used in developed countries compared to the typical antipsychotics, are not in the list; no selective serotonin re-uptake inhibitor except fluoxetine; lithium carbonate-the only true mood stabilizer-is in the restricted list; only one depot neuroleptic-fluphenazine-is in the list, and so on [14]. Psychiatric prescriptions in most centres in Nigeria follow mainly current global evidence-based practice with little or no consideration to our EDL, and stocking follows suit.

\section{Benefit package}

One of the items in the NHIS benefit package to the contributors is the provision of hospital care in a standard ward for a stay limited to cumulative 15 days per year. Thereafter, the beneficiary and/or the employer pay (s). Fifteen days per year! Most mentally-ill patients that merit admission would stay beyond 15 days per admission. Occupational rehabilitation, as well as some behavioural therapies, for instance, is an integral part of mental health treatment and usually takes long periods (in some cases months).

\section{Healthcare professionals}

Here, some relevant professionals in the mental health team like clinical psychologists, psychiatric social workers, and occupational therapists were excluded. The contributions of these vital mental health team members to comprehensive health care delivery to the mentally-ill cannot be overemphasized.

\section{Specialist mental clinics}

While specialist clinics like dental, physiotherapy, ENT, eye, and so on are recognized and specified in the scheme (some even as in-house or stand-alone clinics), clinics that render mental health services such as psychotherapy clinics, addiction clinics, special counseling clinics, and so on were not listed.

\section{Mental Health Services in South-East Nigeria}

Officially, public institutions where mental health services can currently be accessed in the zone are: six federal tertiary hospitals (1 Psychiatric hospital in Enugu; 3 teaching hospitals in Abakaliki, Enugu and Nnewi; and 2 medical centres in Owerri and Umuahia), plus four state hospitals (4 teaching hospitals in Aba, Awka, Enugu, and Orlu; and 2 stand-alone psychiatric outfits in Mgbokor in Abia state and Nawfia in Anambra state). Private psychiatric centres (whether owned by individuals or by groups like religious organizations) are sparse in the area. The hospitals and professionals on ground in the Psychiatry departments of these institutions as at May, 2017 are as estimated in the Table 1 below. 
Table 1. Distribution of mental health professionals in public hospitals in south-east Nigeria.

\begin{tabular}{|c|c|c|c|c|c|c|c|c|}
\hline State & Hospital & $\begin{array}{l}\text { Psychiatrists } \\
\text { (Consultants) }\end{array}$ & $\begin{array}{c}\text { Resident } \\
\text { doctors }\end{array}$ & $\begin{array}{c}\text { Clin. } \\
\text { Psychologists }\end{array}$ & $\begin{array}{l}\text { Psychiatric } \\
\text { Nurses }\end{array}$ & OT & $\begin{array}{c}\text { Social } \\
\text { workers }\end{array}$ & Others \\
\hline \multirow{3}{*}{ Abia } & FMC Um & 2 & 0 & 0 & Few & 0 & 0 & \multirow{12}{*}{1} \\
\hline & ABSUTH & 1 & 1 & 0 & Few & 0 & 0 & \\
\hline & Mgbokor & MO & 0 & 0 & Few & 0 & 0 & \\
\hline \multirow{3}{*}{ Anambra } & NAUTH & 2 & 0 & 1 & Few & 0 & 0 & \\
\hline & COOUTH & $2 \mathrm{PT}$ & 0 & 0 & Few & 0 & 0 & \\
\hline & Nawfia & MO & 0 & 0 & Few & 0 & 0 & \\
\hline \multirow[t]{2}{*}{ Ebonyi } & FETHA & 6 & 14 & 6 & Adequate & 0 & 1 & \\
\hline & FNHE & 8 & 25 & 1 & Adequate & 1 & 6 & \\
\hline \multirow[t]{2}{*}{ Enugu } & UNTH & 6 & 4 & 2 & Few & 0 & 0 & \\
\hline & ESUTTH & 3 & 4 & 3 & Few & 0 & 4 & \\
\hline \multirow{2}{*}{ Imo } & FMC Ow & 1 & 0 & 0 & Few & 0 & 0 & \\
\hline & IMSUTH & 1 & 0 & 0 & Few & 0 & 0 & \\
\hline
\end{tabular}

Key: (See the abbreviation list). "Social workers" here refer to trained psychiatric social workers attached to mental health departments of the respective institutions. "Others" include, for instance, Special Educationists. "Few" refers to below average number; "adequate" refers to at least average.

In all, the zone has only about 30 full time psychiatrists and only about 12 clinical psychologists on ground in public hospitals attending to patients and residents of over 16 million people in the zone [15]. These figures are far below the number in some other zones in the country like the south-western zone of Nigeria. So, our brothers in the south-western part of the country seem to have appreciated mental health services better and have gone far ahead. That is commendable. Again, this number of psychiatrists, for instance, compares favourably with the number of some specialists (e.g., gynaecologists) in some single tertiary hospitals within the same south-east zone. The question remains whether in the south-east Nigeria we do not have people who need mental health services or whether we do not yet see the need to employ mental health experts in our public health institutions? The latter seems more likely.

All the few mental health professionals in service are in tertiary hospitals with one psychiatrist (not shown in the table) in a university medical centre and few other clinical psychologists in the universities as lecturers (many, not necessarily out of choice but because they could not be absorbed in the hospitals or when absorbed, they are not satisfactorily placed or remunerated).

None of the five states has an effective functional community psychiatry services. Only few psychiatric nurses (not represented in the table above) are in some state general hospitals practising general nursing and there are no mental health professionals in the primary health facilities such as health centres despite the name "Comprehensive" Health Centres that some of them answer.

There is a problem with mental health professionals in the area in terms of "availability" and distribution. But the low manpower of these professionals is not really because of non-availability of qualified personnel in the zone but for 
many factors, most prominent being the unwillingness of our hospital chief executives/administrators to face reality. As at the time of this documentation, some post-part II psychiatry Fellows (medical doctors who had completed their specialist training in Psychiatry), as well as trained clinical psychologists in the area, have been roaming about looking for job even up to the far away insurgency-overtaken feared north-eastern Nigeria. Many of our employers have not seen the need to employ psychiatrists, clinical psychologists, occupational therapists, or psychiatric social workers or nurses. The implication of this paucity of engagement of mental health professionals, not only on the part of the mentally-ill and their families, but also on the entire workforce and economic growth of the area, is unimaginable. Very unfortunate!

\section{The Way Forward}

For Nigeria to achieve a universal health coverage, every zone must be covered and mental health, as important as (if not more important than) physical health, must be adequately incorporated in the programmes. The September 2015 summit was a good one. Efforts should be made to ensure that the issues discussed during the summit and the proffered ways to ameliorate or tackle the identified challenges, are implemented.

Stigma: Stigmatization and discrimination of the mentally-ill as well as mental health professionals is a global issue. The mentally-ill is not a failure neither is he the cause of his illness. Indeed, a former Director-General of the World Health Organization DrGro Harlem Brundtland once said that "Mental illness is not a personal failure. In fact, if there is failure, it is to be found in the way we have responded to people with mental and brain disorders" [4]. All, especially the elites and in particular health professionals should say "No" to stigmatization of the mentally-ill. Patients and mental health professionals should also avoid self-stigmatizations. The professionals should be proud of their profession anywhere, any time.

Advocacy: All health professionals should be involved in advocacy processes in favour of the mentally-ill. Policy makers in all aspects of government or administration in the zone should advocate for the welfare of the mentally challenged.

Engagement: Our hospital administrators/chief executives should, please wake up to the reality and employ mental health professionals. Almost every patient needs the services of this group of health professionals. Mental health professionals (psychiatrists, clinical psychologists, psychiatric nurses, psychiatric social workers, occupational therapists, special educationists, etc) are needed in every hospital, be it tertiary, secondary, or primary centres or whether federal, state, or private-owned.

Motivation: Motivation/encouragement of all mental health workers is vital. Special allowances should be paid to this group of professionals in lieu of the nature of their job.

NHIS: In a Presidential Summit on universal health coverage (UHC) held in Abuja, Nigeria on Monday, $10^{\text {th }}$ March, 2014, it was emphasized that for the 
universal health coverage to be a reality in Nigeria, health insurance must be a compulsory policy. The federal government reaffirmed her political commitment towards providing equitable, qualitative, and universally acceptable healthcare for all Nigerians without people suffering financial hardship. There is no doubt that much improvement has been recorded in the sector since after the summit. However, a lot is still required especially as it affects the mentally-ill, most of who, like in most chronic physical conditions, were not responsible for their ailments.

A good number of the mentally-ill, unlike those with chronic physical conditions, are unemployed. Even the few that are employed are usually not given all opportunities to grow in their jobs like others (out of stigma) and some are easily dismissed by their employers on a slight knowledge of the person's ailment. The insurance scheme should be improved further on the aspects pertaining to the mentally-ill. Persons with severe chronic mental disorders like schizophrenia should be recognized in the scheme as a vulnerable group and be categorized and treated in the same manner like other vulnerable groups (such as the physically challenged, prison inmates, children under five, refugees, internally displaced persons, pregnant women, and so on) who are already recognized in the scheme as a vulnerable group. Governments could equally go ahead to accommodate free or much-reduced treatments for those with chronic major mental disorders especially the unemployed non-contributors to the scheme. Packages of the scheme should also be adjusted favourably for the mentally-ill, such as the extension of the maximum period of admission currently allowed in the scheme as well as the inclusion of mental health clinics in the specialist clinics of the scheme.

The Essential Drug List: This should be revised and expanded to capture more commonly used psychiatric medications. The availability of essential psychotropic drugs in virtually all service and NHIS-approved centres should be ensured. That is essential if the national health insurance policy of the country is to be made effective and reliable.

Care for all: Every tier of government should truly provide for the mentally-ill especially those of them that are homeless, poor, unemployed, and mentally abnormal offenders.

Home visits: Attention in developed countries is shifting from hospital-based to community- and home-based mental health services. That is a prerequisite to achieving universal coverage in mental health. Hospitals where we have mental health professionals in the zone should make arrangements for such coverage within their locality. Governments at all levels should factor these while budgeting and should make the necessary legislation that would cover such services.

Financing: Each state in the South-East should have a Mental Health Policy irrespective of whatever exists at the national level and budget and implement effectively for mental health services.

Non-governmental organizations (NGOs): Non-governmental organizations should get interested in mental health matters and prioritize them. Those already in existence should do more, be appreciated, and many more encouraged 
to spring up.

Research: The bedrock of scientific development lies in research. Only few areas in mental health have been studied in the zone. More researches in mental health are encouraged.

Integration into Primary care: Each state of the South-East Nigeria should properly integrate mental health into her Primary Healthcare and employ mental health professionals into same. This integration should not just be theoretical or political but should be seen to be practical.

Integration of mental health services into primary healthcare and support of professionals from tertiary institutions: In the meantime, since the bulk of the few specialists are in the specialist and university teaching hospitals, arrangements should be made for a continual support from the centres to other health facilities within the zone, especially the secondary and primary service centres including mission hospitals, as these establishments are major service centres in the area patronized by many with physical conditions. That is, each state or local government within the zone should get mental health services integrated into her primary healthcare and design a model that would involve the training of primary healthcare workers to recognize and treat some psychiatric disorders as well as the involvement of those specialists to periodically visit the primary centres. Subsequently, these tiers of government should endeavor to employ their own specialists.

Adoption of the WHO Mental Health Gap Action Programme (mhGAP): This WHO beautiful concept that aims at scaling up care for mental, neurological, and substance use disorders addresses eight priority conditions: depression, schizophrenia and other psychotic disorders, suicide, epilepsy, dementia, disorders due to use of alcohol, disorders due to use of illicit drugs, and mental disorders in children [16]. Each state of the south-eastern Nigeria should key into this laudable programme.

The Mental Health Bill: Though a national issue, the zone, either collectively or at individual state levels, should contribute tirelessly to the actualization of this bill being passed at the national assembly. States should add weight to the passage of this bill that has been lingering over the years and the Houses of Assembly can also make non-conflicting laws favouring the treatment and protection of the rights of the mentally-ill in their states. The Mental Health Bill, if passed into law, will undoubtedly be beneficial to every Nigerian.

The Sustainable Development Goals (SDGs): The Millennium Development Goals (MDGs) were set by the United Nations back in 2000 at the Millennium Summit where the world leaders adopted the UN Millennium Declaration which committed the nations of the world to a new global partnership, aimed at reducing extreme poverty and other time-bound targets, with a stated deadline of 2015 [17]. Nigeria, like most other nations of the world, signed this treaty and promised to work towards the realization of these goals and for her to achieve this, a number of steps were taken, including the release of funds by the federal government as well as the creation of offices and appointment of individuals to 
key positions to work towards the MDG targets [18]. Each of the eight goals had a direct or indirect link to mental health and wellbeing. Unfortunately, however, the target period expired with not much being achieved in most sub Saharan African nations including Nigeria (in which the south-east geopolitical zone is an integral part) due to a multiplicity of health system-related, political and systemic challenges [19]. The impact of this below average achievement on the mental health of the populace is enormous. The more all-encompassing 17 Sustainable Development Goals which now replace the MDGs [20] have a concluding pledge that "no one will be left behind". Actualizing these goals in south-east Nigeria will mean promoting the mental health of the people of the area and primarily preventing future mental disorders. While this is being done, those already inflicted with mental disorders should not be left behind but rather should equally derive benefits from the goals (and their targets) which (in) directly provide secondary and tertiary preventions to such persons. Indeed, as Oleribe and Robinson [18] advised, now is the time to do things differently in Nigeria, the south-east inclusive.

\section{Conclusion}

There is no health without mental health. Mental health services in the SouthEast Nigeria are still far below the internationally required standard. To achieve complete health coverage and healthy lives for the people of the South-East Nigeria, we should focus on, not only physical conditions or communicable diseases but also on mental health and mental disorders. All measures that would ensure thepromotion of mental health, prevention and treatment of mental disorders, and appropriate rehabilitation of those with mental illnesses in our zone must be adopted and pursued vigorously. May we wake up and join the rest of the world.

\section{Acknowledgements}

The authors are very grateful to the personnel/staff of the various hospitals that helped in providing information on the professional staff strength of the various institutions mentioned. Any disparity in the figure provided and the actual number on ground (especially if further employments were made between the time of data gathering and this publication) is highly regretted and we seriously apologize for that.

\section{Conflicts of Interest}

There are no conflicts of interest.

\section{Financial Support and Sponsorship}

Nil.

\section{References}

[1] Alwan, A. (2008) World Health Organization. Mental health Global Action Pro- 
gramme: mhGAP — Scaling up Care for Mental, Neurological, and Substance Use Disorder. World Health Organization, Geneva, Switzerland.

http://www.who.int/mental_health/mhgap_final_english.pdf

[2] World Health Organization (2005) World Health Assembly Resolution: Sustainable Health Financing, Universal Coverage, and Social Health Insurance. World Health Organization, Geneva, WHA 58.33. http://apps.who.int/medicinedocs/documents/s21475en/s21475en.pdf

[3] Rodney, A.M. and Hill, P.S. (2014) Achieving Equity within Universal Health Coverage: A Narrative Review of Progress and Resources for Measuring Success. International Journal for Equity in Health, 13, 72.

https://doi.org/10.1186/s12939-014-0072-8

[4] World Health Organization (2001) Mental Disorders Affect One in Four People. A Product of NMH Communications. World Health Organization, Geneva.

http://www.who.int/whr/2001/media_centre/press_release/en/

[5] World Health Organization (2005) Mental Health Atlas 2005. Geneva, Switzerland, World Health Organization.

http://www.who.int/mental_health/evidence/mhatlas05/en/

[6] World Health Organization (2008) Mental Health Global Action Programme: mhGAP - Scaling up Care for Mental, Neurological, and Substance Use Disorder. World Health Organization Geneva, Switzerland. http://whqlibdoc.who.int/publications/2010/9789241548069_eng.pdf

[7] Gureje, O., Chisholm, D., Kola, L., Lasebikan, V. and Saxena, S. (2007) Cost-Effectiveness of an Essential Mental Health Intervention Package in Nigeria. World Psychiatry, 6, 42-48. https://www.ncbi.nlm.nih.gov/pmc/articles/PMC1805717/PMCID

[8] Urigwe, S.E. (2010) Understanding Mental Illness in Nigeria: Bringing Culture and Traditional Medicine into Mental Health Policy. Texas Medical Center Dissertations (via ProQuest). 2010 Paper AAI1495488.

http://www.proquest.com/products-services/pqdtglobal.html

[9] World Health Organization (2015) Health in 2015: From MDGs to SDGs. World Health Organization, Global Health Observatory Data, Geneva.

http://www.who.int/gho/publications/mdgs-sdgs/en/

[10] WHO/FMOH (2006) A Report of the Assessment of Mental Health System in Nigeria Using the World Health Organization-Assessment Instrument for Mental Health Systems (WHO-AIMS).

http://www.who.int/mental_health/evidence/nigeria_who_aims_report.pdf

[11] Federation of Nigeria (1999) National Health Insurance Scheme Decree No 35 of 1999, Laws of the Federation of Nigeria. http://www.nigeria-law.org/NationalHealthInsuranceSchemeDegree.htm

[12] Onoka, C.A., Onwujekwe, O.E., Uzochukwu, B.S. and Ezumah, N.N. (2013) Promoting Universal Financial Protection: Constraints and Enabling Factors in Scaling-Up Coverage with Social Health Insurance in Nigeria. Health Research Policy and Systems, 11, 20. https://doi.org/10.1186/1478-4505-11-20

[13] National Health Insurance Scheme, Abuja. http://www.nhis.gov.ng/

[14] Federal Republic of Nigeria (2010) Essentials Medicines List. 5th Edition, Federal Ministry of Health, Abuja, Nigeria in Collaboration with World Health Organization and European Commission, Abuja, 34-48. http://www.health.gov.ng/doc/EML.pdf

[15] Nigeria Master Web (2006) Nigerian Population. http://www.nigeriamasterweb.com/Nigeria06CensusFigs.html 
[16] World Health Organization (2002) Mental Health Global Action Programme: MhGAP. World Health Organization, Geneva.

[17] United Nations Millennium Project (2015) What They Are. http://www.unmillenniumproject.org/goals/index.htm

[18] Oleribe, O.O. and Taylor-Robinson, S.D. (2016) Before Sustainable Development Goals (SDG): Why Nigeria Failed to Achieve the Millennium Development Goals (MDGs). Pan African Medical Journal, 24, 156.

[19] Sachs, J.D. and McArthur, J.W. (2005) The Millennium Project: A Plan for Meeting the Millennium Development Goals. The Lancet, 365, 347-353.

https://doi.org/10.1016/S0140-6736(05)70201-4 http://dx.doi.org/10.1016/S0140-6736(05)17791-5

[20] United Nations Millennium Project (2015) From MDGs to SDGs. http://www.sdgfund.org/mdgs-sdgs 


\section{List of Abbreviations}

ABSUTH: Abia State University Teaching Hospital, Aba

AIDS: Acquired Immune Deficiency Syndrome

COOUTH: Chukwuemeka Odumegwu Ojukwu University Teaching Hospital, Awka

DALYS: Disability-adjusted life years

EDL: Essential Drug List

ENT: Ear, nose, and throat (Otorhinolaryngology)

ESUTTH: Enugu State University (of Science and) Technology Teaching Hospital FETHA: Federal Teaching Hospital, Abakaliki

FMC: Federal Medical Centre

FMOH: Federal Ministry of Health

FNHE: Federal Neuropsychiatric Hospital, Enugu

HIV: Human Immunodeficiency Virus

HSF: Health Systems Forum

IMSUTH: Imo State University Teaching Hospital, Orlu

MDGs: Millennium Development Goals

mhGAP: WHO Mental Health Gap Action Programme

MNS: Mental, Neurological, and Substance use disorders

MO: Medical Officers

NAUTH: Nnamdi Azikiwe University Teaching Hospital, Nnewi

NGOs: Non-governmental organizations

NHIS: National Health Insurance Scheme

Ow: Owerri

OT: Occupational Therapist

PT: Part time

SDGs: Sustainable Development Goals

UHC: Universal Health Coverage

Um: Umuahia

UNTH: University of Nigeria Teaching Hospital, Ituku-Ozalla

WHO: World Health Organization 
Submit or recommend next manuscript to SCIRP and we will provide best service for you:

Accepting pre-submission inquiries through Email, Facebook, LinkedIn, Twitter, etc. A wide selection of journals (inclusive of 9 subjects, more than 200 journals)

Providing 24-hour high-quality service

User-friendly online submission system

Fair and swift peer-review system

Efficient typesetting and proofreading procedure

Display of the result of downloads and visits, as well as the number of cited articles Maximum dissemination of your research work

Submit your manuscript at: http://papersubmission.scirp.org/

Or contact ojpsych@scirp.org 